\title{
Shallow shear-wave reflection seismics in the tsunami struck Krueng Aceh River Basin, Sumatra
}

\author{
U. Polom ${ }^{1}$, I. Arsyad ${ }^{2}$, and H.-J. Kümpel ${ }^{1}$ \\ ${ }^{1}$ Leibniz Institute for Applied Geosciences, PO Box 510153, Stilleweg 2, 30655 Hannover, Germany \\ ${ }^{2}$ Dinas Pertambangan dan Energi, Jalan T. Nyak Arief No. 195, 23114 Banda Aceh, Indonesia
}

Received: 18 June 2007 - Revised: 5 November 2007 - Accepted: 10 November 2007 - Published: 2 January 2008

\begin{abstract}
As part of the project "Management of Georisk" (MANGEONAD) of the Federal Institute for Geosciences and Natural Resources (BGR), Hanover, high resolution shallow shear-wave reflection seismics was applied in the Indonesian province Nanggroe Aceh Darussalam, North Sumatra in cooperation with the Government of Indonesia, local counterparts, and the Leibniz Institute for Applied Geosciences, Hanover. The investigations were expected to support classification of earthquake site effects for the reconstruction of buildings and infrastructure as well as for groundwater exploration. The study focussed on the city of Banda Aceh and the surroundings of Aceh Besar. The shear-wave seismic surveys were done parallel to standard geoengineering investigations like cone penetrometer tests to support subsequent site specific statistical calibration. They were also partly supplemented by shallow p-wave seismics for the identification of (a) elastic subsurface parameters and (b) zones with abundance of groundwater. Evaluation of seismic site effects based on shallow reflection seismics has in fact been found to be a highly useful method in Aceh province. In particular, use of a vibratory seismic source was essential for successful application of shear-wave seismics in the city of Banda Aceh and in areas with compacted ground like on farm tracks in the surroundings, presenting mostly agricultural land use areas. We thus were able to explore the mechanical stiffness of the subsurface down to $100 \mathrm{~m}$ depth, occasionally even deeper, with remarkably high resolution. The results were transferred into geotechnical site classification in terms of the International Building Code (IBC, 2003). The seismic images give also insights into the history of the basin sedimentation processes of the Krueng Aceh River delta, which is relevant for the exploration of new areas for construction of safe foundations of buildings and for identification of fresh water aquifers in the tsunami flooded region.
\end{abstract}

Correspondence to: U. Polom

(ulrich.polom@gga-hannover.de)

\section{Introduction}

In order to determine near surface seismic velocities for the purpose of earthquake microzonation studies in densely populated urban regions in Europe, a non invasive method i.e. shallow shear-wave reflection seismics has been further developed over the last years at Leibniz Institute for Applied Geosciences, Hanover. The method, in principal, is based on the vibroseis technique commonly applied in the hydrocarbon exploration industry. Ongoing research into this method was initialized by publication of the definitions of the International Building Code (International Code Council, 2003), the Eurocode 8 (2004) and other national building codes (e.g. German Code DIN EN 4149, 2005, and others). They all address the classification of local site effects from earthquake shaking. As an alternative to the common geotechnically defined standard penetrometer test (SPT), the mean shear-wave velocity down to $30 \mathrm{~m}$ depth (VSav30) has been introduced in the Building Codes. The VSav30 parameter provides a physically more appropriate description of the dynamic subsurface soil behaviour than other quantities. Identification of the shallow shear-wave velocities down to $30 \mathrm{~m}$ depth, therefore, has become an important issue in earthquake hazard site effect studies worldwide. Similar investigations using active seismic sources have previously been initiated in e.g. Japan (Inazaki, 1999, 2006) and the US (Purgin et al., 2002). Moreover, various passive source methods are available or are currently still under development, respectively.

So far, shear-wave seismic methods like shear-wave vertical seismic profiling (VSP), shear-wave refraction profiling and shear-wave reflection profiling have not widely been used, mostly due to the lack of adequate equipment. Successful shear-wave VSP operation requires an uncased borehole or erection of a borehole that is enlarged by a specific plastic tube casing. While VSP is the most reliable way to obtain information on the shear-wave velocity - depth distribution, because of the one way ray path, it is often also the most ex-

Published by Copernicus Publications on behalf of the European Geosciences Union. 


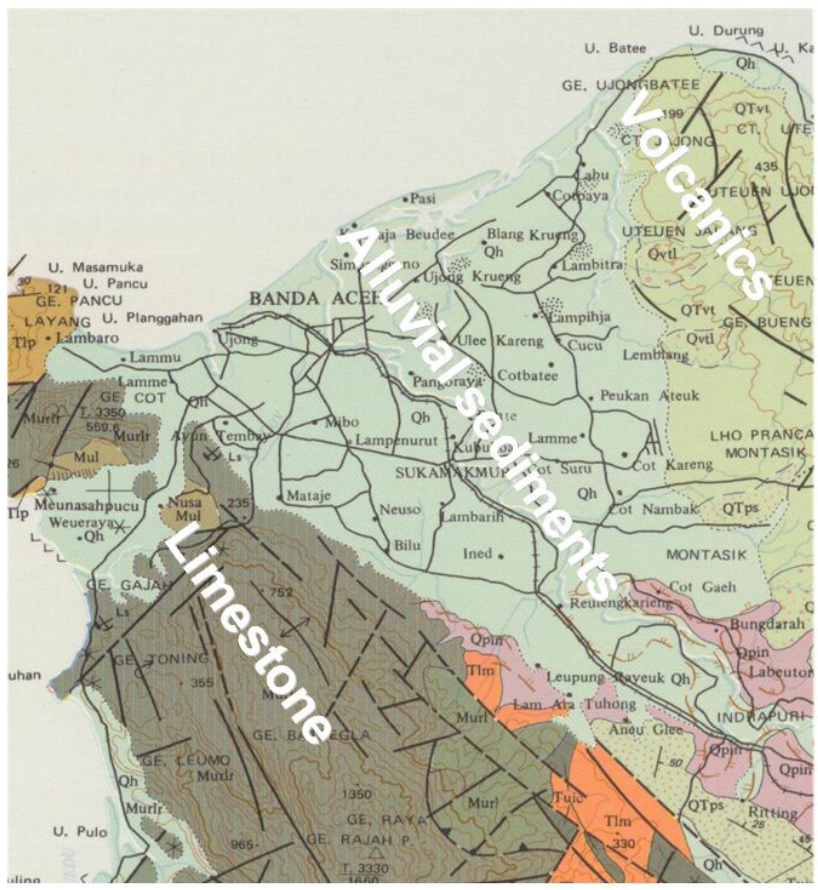

Fig. 1. Scene of the geologic map (Bennett et al., 1981) of the Krueng Aceh River delta showing undifferentiated alluvial sediments in the whole investigation area, adjacent to volcanic rocks (NE) and limestones (SW). Post tsunami ground-water exploration drilling in the alluvial delta has yielded stacks of organic clay, silt, sand, and gravel down to a depth of $220 \mathrm{~m}$.

pensive approach, due to the drilling costs. Common seismic refraction analysis often leads to poor results due to a discontinuously increasing velocity-depth distribution of shearwaves. Steadily increasing velocities with depth are, however, required for the successful application of the refraction method. Otherwise, false interpretations will often be the consequence. With p-waves, the situation is different; they generally present increasing velocities with depth. For instance, at the ground water level the p-wave velocities mostly rise, while shear-wave velocities remain unaffected as they are hardly affected by the presence of pore fluids. In fact, the lack of a continuously increasing velocity-depth function for shear-waves results in many cases to the formation of a high velocity channel wave, which is then often misinterpreted as the half space velocity of the bedrock. Yet, through application of the shear-wave reflection method, velocity inversions can also be detected.

Within the project "Management of Georisk" (MANGEONAD) of the Federal Institute for Geosciences and Natural Resources (BGR), Hanover, high resolution shallow shear-wave reflection seismics was applied in the Indonesian province Nanggroe Aceh Darussalam, North Sumatra in cooperation with the Government of Indonesia, local counterparts, and the Leibniz Institute for Applied Geosciences, Hanover. The investigations were applied together with en-

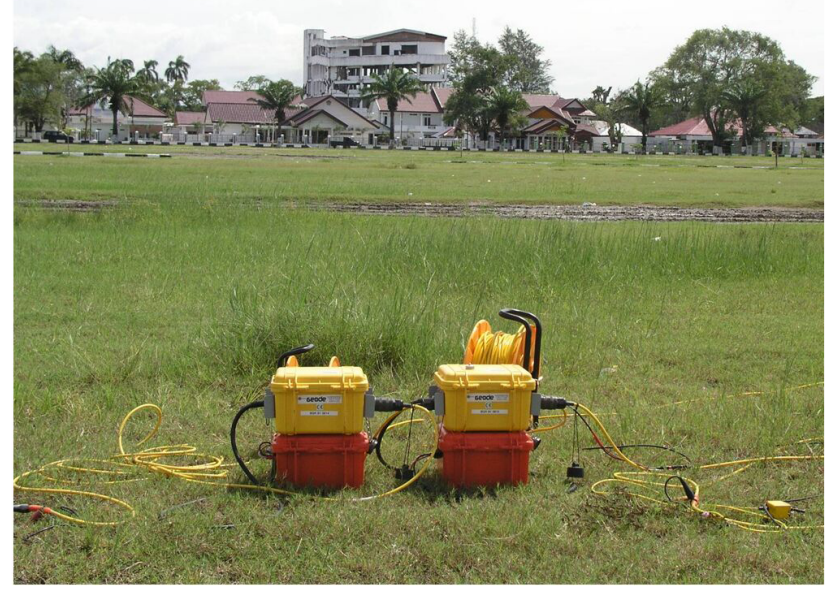

Fig. 2. Shallow shear-wave site investigation at Blang Padang place, centre of Banda Aceh city. Foreground: 48 channel Geode system used for seismic data acquisition. Centre: Local mud zone indicating local subsidence of young sediments. Background: Houses of nearly traditional Indonesian building style that were only slightly affected by earthquake shakings. In contrast, the high concrete building (demolition in 2006) shows severe structural damages and partly total collapse due to the earthquake shaking of 26 Dec 2004.

gineering geology and hydrogeologic studies. Knowledge of shallow soil conditions and of the subsurface layer structuring is important to understand the complex subsurface behaviour in the tsunami affected Krueng Aceh River region (Fig. 1). Such knowledge is required for reconstructing safe buildings, sustainable lifelines and infrastructure. Our investigations were not only restricted to fulfil the terms of the Building Codes, but should also contribute to a multidisciplinary approach of the overall restoration of the area. Moreover, application of several methods was aimed to reduce uncertainties in the individual results. The seismic results were integrated into a database called Information System Engineering Geology (ISEG) developed by BGR. The database is also hosting the available borehole information, geotechnical cone penetrometer testings (CPT) and data from laboratory analysis of soil and rock samples. In its final stage, ISEG will allow 3D visualization of geotechnical parameters of the various subsurface units in the investigation area.

\section{Method}

The high resolution shallow shear-wave reflection technique we applied uses specific equipment which can partly not be purchased from standard suppliers. Unlike shear-wave geophones that are widely in use in the hydrocarbon exploration industry, shear-wave seismic sources for engineering purposes are not commonly available but are still under development at a few institutions. As shear-wave impulsive sources are affected by problems of signal repeatability, trigger accu- 
Table 1. Seismic recording parameters.

\begin{tabular}{ll}
\hline Period & 20 Nov-12 Dec 2005 \\
Instrument & GEOMETRICS GEODE \\
Channels/record & 48 \\
Shot locations & 49 \\
Seismic source & GGA wheel barrow mounted shear-wave source system \\
Sweep type & 20-200 Hz linear, 10 s, 100 ms taper at both sides \\
Recording & $12 \mathrm{~s}(2 \mathrm{~s}$ after correlation $)$ \\
Sampling interval & 2 ms \\
Recording filter & Out \\
Spread type & 2-D variable split spread, SH-SH configuration, fixed receiver setup \\
Geophone type & SM $6 \mathrm{H}(10 \mathrm{~Hz})$, single units \\
Receiver interval & 2(1) m \\
Source interval & $2(1) \mathrm{m}$ \\
Vertical stack & 4-fold $[+2 \mathrm{Y}]-[-2 \mathrm{Y}]$ alternated vibrations \\
\hline
\end{tabular}

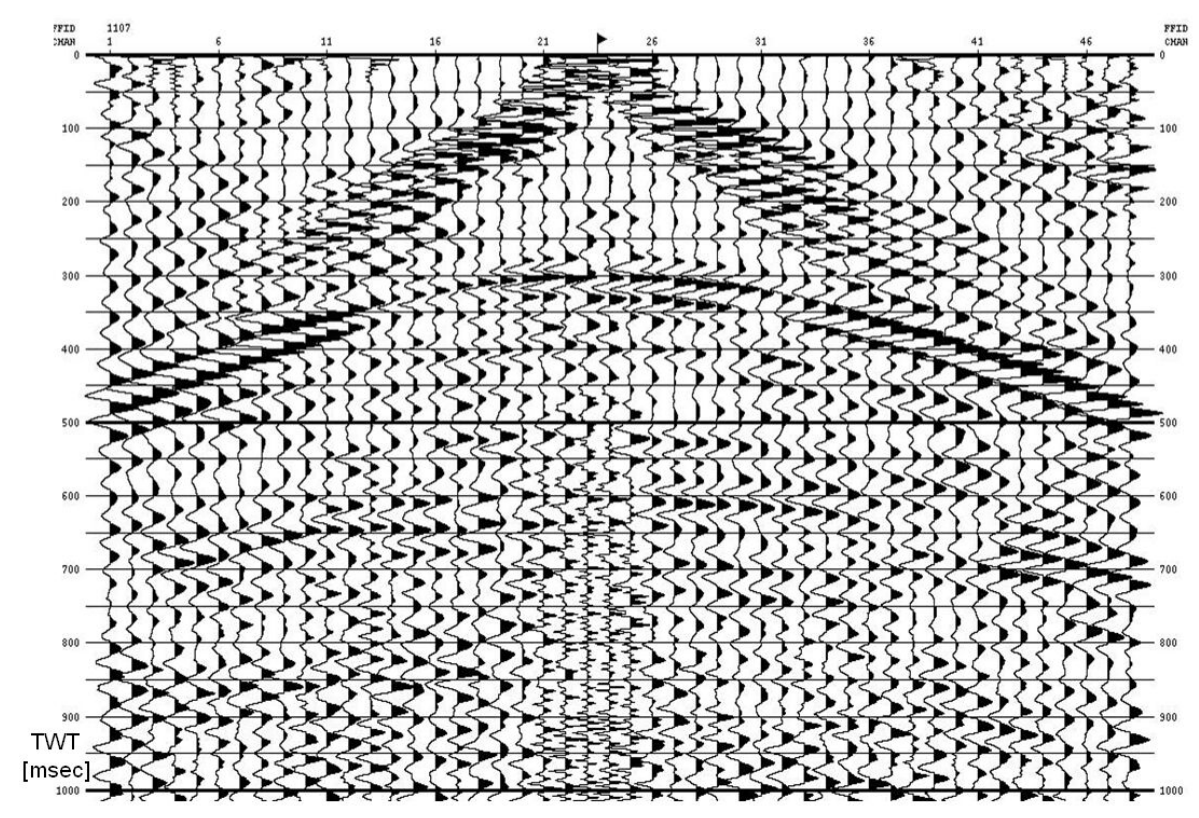

Fig. 3. Example of correlated raw record of horizontal shear-waves at profile location Lam Saiun in the centre of the alluvial delta ( $2 \mathrm{~m}$ geophone spacing, $96 \mathrm{~m}$ total spread). The record shows a clear shear-wave reflection hyperbola of $135 \mathrm{~m} / \mathrm{s} \mathrm{rms} \mathrm{velocity} \mathrm{at} 300 \mathrm{~ms}$ zero offset, corresponding to a low velocity layer of minimum thickness $20 \mathrm{~m}$. Hyperbolas of later arrivals indicate no significant increase of velocities with depth. Refracted waves as well as the often disturbing Love surface wave are missing due to the presence of compacted soil, i.e. a thin, man made high velocity layer at the surface.

racy, efficient source to ground coupling and present environmental violations, shear-wave vibratory sources have become state-of-the-art technology in the hydrocarbon industry. For engineering purposes, the main advantages of the shear-wave reflection method compared to p-wave investigations are (a) higher resolution of subsurface layers due to the lower velocities resulting in smaller wavelengths and (b) higher potential to image folds and cracks. Moreover, the combination of $\mathrm{p}$ and shear-wave techniques allows for direct fluid and gas detection.
The engineering-type seismic equipment we used includes of a lightweight, highly transportable and flight transportation adapted unit consisting of a modular expandable 48 channel Geometrics GEODE recording system (Fig. 2), sets of single shear- and p-wave geophones and a small, electrodynamically driven shaker source system for the generation of shear-wave vibration sweeps. The whole shaker system is powered by a car battery and is attached to a wheel barrow unit for easy transportation in the field. The full equipment also contains p- and shear-wave hammer blowing units 


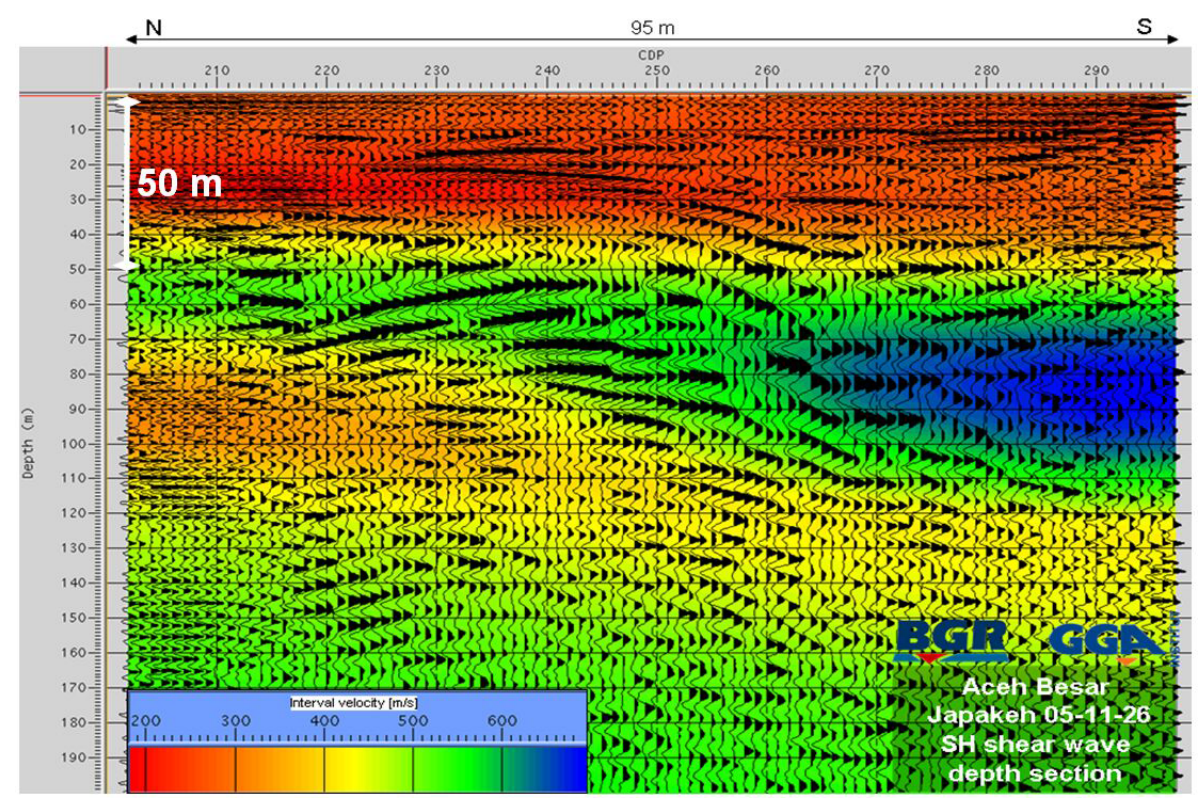

Fig. 4. Depth converted reflection seismic stack section at Japakeh site, colour coded by shear-wave interval velocities derived from reflection seismic stacking velocities. Red colours show low velocity areas whereas blue colors indicate high velocities. Lateral and vertical averaged shear-wave velocity over the top $30 \mathrm{~m}$ (VSav30) is $247 \mathrm{~m} / \mathrm{s}$, indicating IBC class SD of stiff soil. The subsurface structure shows folded layer characteristics and thus some strong tectonic activity in the recent past.

in spare, and a DGPS positioning system. The acquisition parameters for the surveys in North Sumatra are given in Table 1 . The shear-wave system enables to carry out reflection seismics down to depths between $50 \mathrm{~m}$ and $150 \mathrm{~m}$. Frequencies of the shaker system were chosen to range from $10 \mathrm{~Hz}$ to $330 \mathrm{~Hz}$. An example of the acquired seismic raw data is shown in Fig. 3. Subsequent data processing lead to high resolution images of the subsurface stiffness in terms of the shear-wave velocity and layer structure (Fig. 4).

\section{Results and discussions}

Depth converted 2-D sections of the shallow reflection seismic investigations in the Krueng Aceh River Basin show a variety of layer structures in the basin area (Fig. 5). The colour coding of the shear-wave interval velocities and the resultant VSav30 parameters for the individual profiles are self-explanatory. They clearly reflect the heterogenities in mechanical strength within the basin, resulting in VSav30 values of $167 \mathrm{~m} / \mathrm{s}$ corresponding to IBC soft soil class $S_{F}$ in the north near the coastline, up to nearly $500 \mathrm{~m} / \mathrm{s}$ corresponding to IBC stiff soil class $S_{C}$ in the eastern part near the airport. Moreover, whereas profiles in the centre and in the eastern part of the basin display subhorizontal layers, profiles near the SW border of the basin present huge folded or steeply dipping layers (Fig. 5). Assuming a continuously developing fluviatile sedimentation process, mainly produced by the deposits of the Krueng Aceh River, the folding and dipping of the basin sediment layers indicate tectonic forcing at the SW border, which is probably related to the activity of the Great Sumatra Fault (GSF). Especially the dipping that is steadily increasing with depth of layers at Lampasi Enking location indicates sequential compressive stress of the basin layers. This finding reveals a significant compressive component in the overall deformation of the area, different from a pure strike slip movement of the GSF. Clearly, the tectonic deformation at the SW border is archived in the sedimentary sequences adjacent to the GSF. Referring to the considerable changes in the subsurface stress field due to the 2004 Sumatra-Andaman earthquake, a dip-over-age analysis of the sediment layer tectonics may possibly help to recognize future georisk for the whole region.

\section{Conclusions}

The shear-wave reflection seismic site effect evaluation has been found to be a useful tool in the densely populated sedimentary regions of Aceh Province. The studies were able to explore the subsurface stiffness down to $100 \mathrm{~m}$ depth, and has allowed for a geotechnical site classification in terms of the IBC 2003. Moreover, due to the high resolution achieved by the applied technology, the seismic depth section images give detailed insights into the basin sedimentation history of the Krueng Aceh River delta and can thus be used (a) to explore new areas yielding safe foundations of buildings and (b) to 


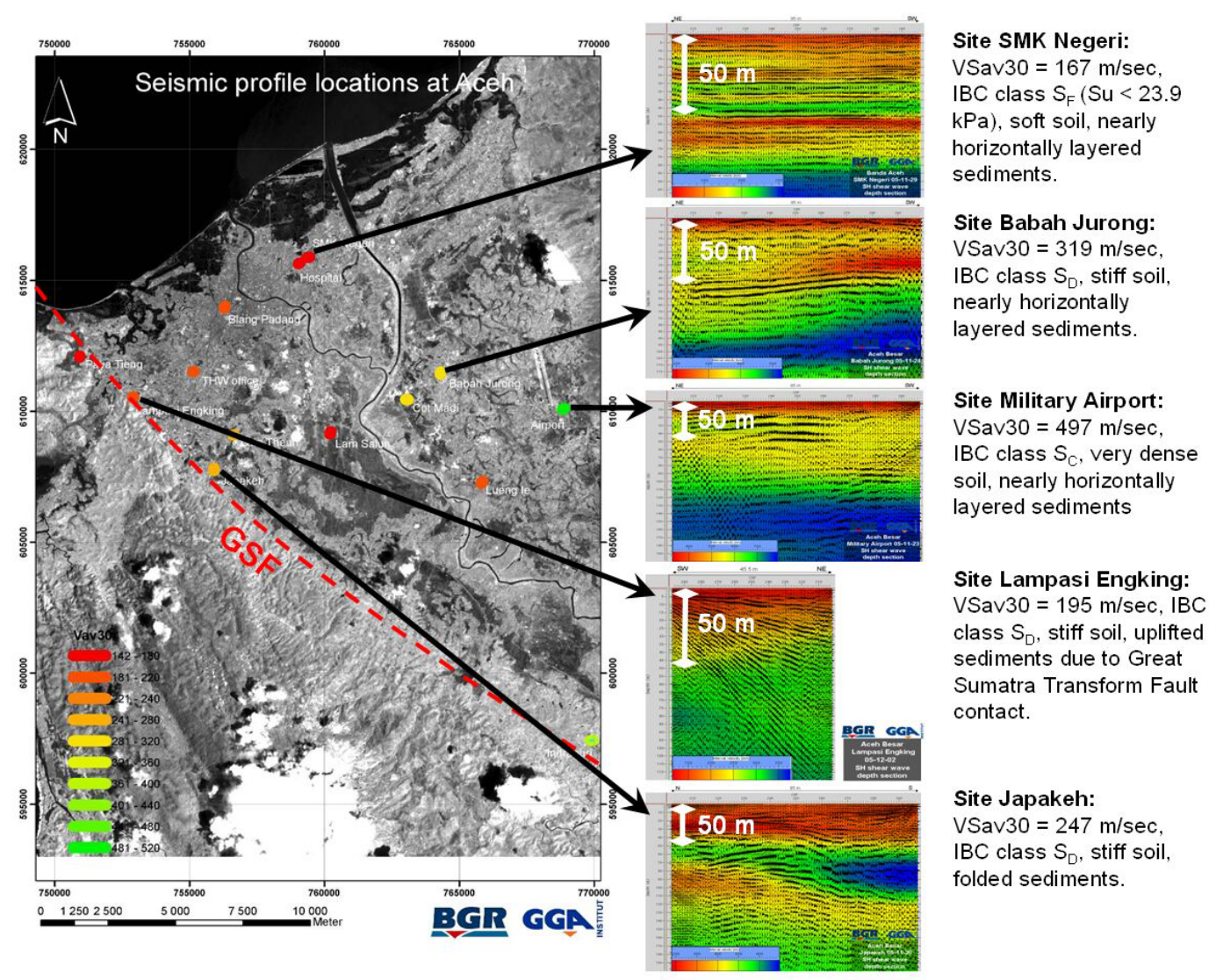

Fig. 5. Preliminary shake risk map based on average shear wave velocity VSav30 (left). Red colours indicate unfavourable soil stiffness concerning building foundation whereas green colours indicate stiff soil. Critical soil conditions were detected for areas near the coastline, especially east of the Krueng Aceh River. Other critical areas - not previously expected - were also found near the river bed in the SE part of the delta. GSF denotes the estimated course of the Great Sumatra Fault at the SW border of the basin. Examples of seismic depth sections (right) show the wide variability of the subsurface structures in the basin area. Note colour scaling has been adapted individually for each depth section due to imaging reasons.

identify prospective layers of water aquifers in the tsunami flooded region.

A small vibratory seismic source was also successfully applied in city like areas and in areas of compacted soil. Man made land fillings here are associated with decreasing velocity gradients at shallow depths, yielding an efficient suppression of Love waves and refracted shear-waves in horizontal shear-wave recordings. The resulting seismic depth sections reveal a surprising variety within the Krueng Aceh Basin sediments: Near the north coast, in the area of Banda Aceh city, mostly horizontally layered soft to very soft sediments were identified. Sediments in the western part are folded, probably due to tectonic activities related to movements of the Great Sumatra fault zone. Sediments in the eastern part, near the volcanic formations, appear to be less critical in terms of earthquake site effects. Further investigations should share more light on the low velocity spots in the centre of the basin.
Acknowledgements. The authors acknowledge the German Ministry of Economic Cooperation and Development and the Republic of Indonesia for funding and supporting this work. Many thanks to T. Rehmann and the staff members of MANGEONAD, Dinas Pertambangan dan Energi, and the Syiah Kuala University of Banda Aceh for their engagement and cooperation during the field campaigns. The authors also thank two anonymous reviewers for helpful suggestions and comments.

Edited by: P. Fabian

Reviewed by: two anonymous referees 


\section{References}

Bennett, J. D., Bridge, D. McC., Cameron, N. R., Djunuddin, A., Ghazali, S. A., Jeffrey, D. H., Kartawa, W., Keats, W., Rock, N. M. S., Thomson, S. J., and Whandoyo, R.: Geologic map of the Banda Aceh quadrangle, Sumatra, Geological Research and Development Centre, Jalan Diponegoro 57, cable P3G, Bandung, Indonesia, 1981.

DIN 4149: Bauen in deutschen Erdbebengebieten - Lastannahmen, Bemessung und Ausführung üblicher Hochbauten, Deutsches Institut für Normung, Beuth-Verlag GmbH, Berlin, 2005 (in German).

Eurocode 8: Auslegung von Bauwerken gegen Erdbeben Teil 1: Grundlagen, Erdbebeneinwirkungen und Regeln für Hochbauten, Deutsche Fassung EN 1998-1, Beuth-Verlag $\mathrm{GmbH}, 2004$ (in German).
Inazaki, T.: Land Streamer: a new system for high-resolution swave shallow reflection surveys, Ann. Symp. Environ. Engin. Geophys. Soc. (SAGEEP) Expanded Abstracts, 207-216, 1999.

Inazaki, T.: High-resolution S-wave reflection survey in urban areas using a woven belt type land streamer, Near Surface 2006, September 4-6, Helsinki, Finland, A016, 2006.

International Code Council: International Building Code 2003, ISBN-10 1892395568, ISBN-13 9781892395566, 2003.

Purgin, A., Larson, T., and Phillips, A.: Shallow high-resolution shear-wave seismic reflection acquisition using a land-streamer in the Mississippi River floodplain: potential for engineering and hydrogeologic applications, SAGEEP 2002, February 1014, Las Vegas, Nevada, Publication on CD, 2002. 